\title{
Traumatic Injury to the Immature Frontal Lobe: A New Murine Model of Long-Term Motor Impairment in the Absence of Psychosocial or Cognitive Deficits
}

\author{
Chien-Yi Chen ${ }^{a, e-g}$ Linda J. Noble-Haeusslein ${ }^{a, b}$ Donna Ferriero ${ }^{c, d}$ \\ Bridgette D. Semple ${ }^{a, h}$
}

Departments of a Neurological Surgery, ${ }^{\mathrm{b}}$ Physical Therapy and Rehabilitation Science, ${ }^{\mathrm{C} P e d i a t r i c s}$ and ${ }^{\mathrm{d}}$ Neurology, University of California, San Francisco, San Francisco, Calif., USA; ${ }^{\mathrm{e}}$ National Taiwan University Hospital, ${ }^{\mathrm{f}}$ National

Taiwan University College of Medicine, and ${ }^{9}$ Graduate Institute of Clinical Medicine, Taipei, Taiwan, ROC;

${ }^{\mathrm{h}}$ Department of Medicine (Royal Melbourne Hospital), Melbourne Brain Centre, University of Melbourne,

Melbourne, Vic., Australia

\section{Key Words}

Traumatic brain injury · Frontal lobe · Behavior · Pathology .

Development · Motor deficit

\begin{abstract}
Traumatic brain injury in children commonly involves the frontal lobes and is associated with distinct structural and behavioral changes. Despite the clinical significance of injuries localized to this region during brain development, the mechanisms underlying secondary damage and long-term recovery are poorly understood. Here, we have characterized the first model of unilateral focal traumatic injury to the developing frontal lobe. Male C57BI/6J mice at postnatal day (p)21, an age approximating a toddler-aged child, received a controlled cortical impact or sham surgery to the left frontal lobe and were euthanized 1 or 7 days later. A necrotic cavity and local inflammatory response were largely confined to the unilateral frontal lobe, dorsal corpus callosum and striatum anterior to the bregma. While cell death and accumulated $\beta$-amyloid precursor protein were characteristic features of the pericontusional motor cortex, corpus
\end{abstract}

callosum, cingulum and dorsal striatum, underlying structures including the hippocampus showed no overt pathology. To determine the long-term functional consequences of injury at p21, two additional cohorts were subjected to a battery of behavioral tests in adolescence (p35-45) or adulthood (p70-80). In both cohorts, brain-injured mice showed normal levels of anxiety, sociability, spatial learning and memory. The signature phenotypic features were deficits in motor function and motor learning, coincident with a reduction in ipsilateral cortical brain volumes. Together, these findings demonstrate classic morphological features of a focal traumatic injury, including early cell death and axonal injury, and long-term volumetric loss of cortical volumes. The presence of deficits in sensorimotor function and coordination in the absence of abnormal findings related to anxiety, sociability and memory likely reflects several variables, including the unique location of the injury and the emergence of favorable compensatory mechanisms during subsequent brain development.

\section{KARGER}

E-Mail karger@karger.com

www.karger.com/dne
(C) 2013 S. Karger AG, Basel

0378-5866/13/0356-0474\$38.00/0
Bridgette D. Semple, $\mathrm{PhD}$

Department of Neurological Surgery, University of California, San Francisco 513 Parnassus Avenue, Room HSE-722

San Francisco, CA 94143-0112 (USA)

E-Mail Bridgette.Semple@ ucsf.edu 


\section{Introduction}

Traumatic brain injury (TBI) is a leading cause of long-term disability in children, especially in males under 4 years of age [1]. Young children also show increased vulnerability to injury and the poorest outcomes after TBI, likely due to inherent developmental differences in the immature brain compared to the adult brain, including reduced antioxidant reserves and a prolonged, exacerbated inflammatory response [2-4]. Importantly, neurocognitive deficits often emerge over time in parallel with ongoing brain maturation, potentially interfering with the acquisition of new skills [5]. Lesions to the frontal lobes, frequently seen in young children [6], contribute to impaired executive function, learning and psychosocial disturbances [6-8]. Supporting these findings is evidence that more extensive frontotemporal atrophy, as identified by magnetic resonance imaging, is associated with greater disability in children approximately 2 years after moderate-to-severe TBI [9].

The use of animal models of frontal brain injury has been considerably scarce to date and limited to the adult or aged brain. Traditionally, the most commonly employed TBI models involve impact to the parietal lobes, either unilaterally or bilaterally, although a limited number of studies have applied bilateral controlled cortical impact (CCI) to the frontal lobes of adult and aged rats $[10,11]$. Others are investigating injury mechanisms following a unilateral frontal lobe lobotomy by surgical resection or aspiration in adult mice $[12,13]$. More clinically relevant is a recent modification of the Marmarou impact-acceleration model where an impact is delivered to the anterior cranium of the adult rat. Such an insult produces a characteristic diffuse neuropathology and a reduction in spontaneous exploration for at least 1 week [14].

To the best of our knowledge, there are currently no rodent models of frontal traumatic injury (i.e. CCI, impact-acceleration or fluid-percussion) to the developing brain. Thus, the aim of this study was to establish a new model of traumatic injury to the frontal lobe of the developing mouse brain. Here, we characterize acute and chronic neuropathology and conduct an extensive battery of behavioral assays that collectively profile sensorimotor, cognitive and psychosocial behaviors after CCI to the left frontal lobe at postnatal day (p)21. Our findings reveal a characteristic early necrotic and inflammatory response and a unique signature of motor dysfunction which persists into adulthood, in the absence of cognitive or psychosocial deficits.

Frontal Traumatic Injury to the Developing Brain

\section{Methods}

Animals

All experiments were approved by the Institutional Animal Care and Use Committee at the University of California, San Francisco. All histological and behavioral tasks and analyses were conducted in a randomized and blinded fashion. Male C57BL/6J mice at p17 were purchased with an accompanying lactating mother from The Jackson Laboratory (Bar Harbor, Me., USA) and housed in standard institutional cages on a 12-hour light/12-hour dark cycle with ad libitum access to water and food. A total of 66 mice were used in this study. One animal from the adult (3-month) sham-operated cohort was excluded from the study due to the presence of abnormal ventriculomegaly upon sectioning.

\section{Model}

At p21, pups were weaned and anesthetized by intraperitoneal injection of 1.25\% 2,2,2-tribromoethanol (Avertin) diluted in isotonic saline to $0.02 \mathrm{ml} / \mathrm{g}$ body weight. Animals from each litter were randomly allocated to either TBI or sham operation. Each mouse was secured in a stereotaxic frame (David Kopf Instruments, Tujunga, Calif., USA) and maintained on a circulating water heating pad during surgery. After a midline skin incision was made, a 3.5-mm-diameter circular craniotomy was performed with a dental drill, positioned left of the midline and $0.5 \mathrm{~mm}$ anterior to the bregma [15]. TBI mice were then positioned beneath the injury device (eCCI-6.3, Custom Design and Fabrication, Richmond, Va., USA) and subjected to a CCI injury using a $3.0-\mathrm{mm}$ convex impactor tip with the following parameters: velocity $2.5 \mathrm{~m} / \mathrm{s}$, depth $1.7 \mathrm{~mm}$, for $150 \mathrm{~ms}$. The impactor was angled $5^{\circ}$ lateral from vertical. Following impact, the scalp was sutured and each mouse was administered approximately $1.0 \mathrm{ml}$ of isotonic saline subcutaneously to prevent postoperative dehydration. Sham-operated mice underwent identical surgical procedures, including craniotomy, without the cortical impact. Following surgery, mice were group-housed (4-5 per cage), and weights were monitored weekly.

\section{Tissue Collection and Preparation}

Brains were collected either $24 \mathrm{~h}$ or 7 days after injury for immunohistochemistry and histology (8 TBI mice and 5 sham mice per time point). Brains from two additional cohorts were collected 1 and 3 months after injury ( $n=10$ /group), upon completion of behavioral assessments. Anesthetized mice were perfused transcardially with ice-cold saline followed by $4 \%$ paraformaldehyde in $0.1 \mathrm{M}$ phosphate-buffered saline (PBS). Brains were then removed, postfixed overnight in $4 \%$ paraformaldehyde and transferred into $30 \%$ sucrose for $72 \mathrm{~h}$ before embedding. Serial coronal sections, spanning the entire frontal and parietal lobes, were collected at either $20 \mu \mathrm{m}$ ( $24 \mathrm{~h}$ and 7 days) or $40 \mu \mathrm{m}$ (1- and 3-month cohorts).

\section{Immunohistochemistry}

Immunohistochemistry was performed on $20-\mu \mathrm{m}$ coronal sections ( $\mathrm{n}=5-7$ per brain, $800 \mu \mathrm{m}$ apart). Sections were thawed and immersed in hydrogen peroxide (either $3 \%$ in methanol or $0.3 \%$ in PBS), followed by incubation in blocking solution containing $10 \%$ species-appropriate serum, $0.2 \%$ Triton X-100 and $0.1 \%$ bovine serum albumin in PBS. Sections were then incubated overnight at $4^{\circ} \mathrm{C}$ in serum-containing blocking solution with the following antibodies: polyclonal rabbit anti- $\beta$-amyloid precursor protein ( $\beta$-APP; 1:500; Invitrogen, Grand Island, N.Y., USA), goat anti-Iba-1 (1:500; 
Abcam, Cambridge, Mass., USA), rabbit polyclonal anti-glial fibrillary acidic protein (GFAP; 1:1,000; DAKO, Carpinteria, Calif., USA) or rabbit polyclonal anti-cleaved caspase-3 (1:1,000; Millipore, Billerica, Mass., USA). Biotinylated goat anti-rabbit (1:500; Vector Laboratories Inc., Burlingame, Calif., USA) or horse antigoat IgG (1:200) antibodies were subsequently applied for detection using the Vectastain ABC kit (Vector Laboratories) and nickel-enhanced 3,3'-diaminobenzidine tetrahydrochloride. Staining was visualized using a Nikon Optiphot light microscope with Spot ${ }^{\mathrm{TM}}$ Imaging Solutions software (Sterling Heights, Mich., USA).

\section{Detection of Acute Cell Death}

Fluoro-Jade C (FJC) was used to identify acute cell death. Thawed sections were briefly pretreated with $1 \%$ sodium hydroxide in ethanol and then incubated in $0.06 \%$ potassium permanganate for $10 \mathrm{~min}$, followed by $0.0001 \% \mathrm{FJC}$ in $0.1 \%$ acetic acid for 10 min. Staining was visualized using a Nikon fluorescent microscope for qualitative assessments. Terminal deoxynucleotidyl transferase-mediated dUTP nick 3 '-end labeling (TUNEL) was performed on adjacent sections to quantify dying/dead cells, using the in situ Cell Death Detection kit, POD (Roche Applied Science, Indianapolis, Ind., USA), according to the manufacturer's instructions. All TUNEL-positive cells $24 \mathrm{~h}$ after injury were counted on 5 sections per brain and summed, within defined anatomical regions including the dorsal cortex, hippocampus, striatum and corpus callosum, to evaluate the pericontusional spread of cell death.

\section{Cortical Volume Measurements}

An estimation of intact cortical volumes was performed on 40$\mu \mathrm{m}$ sections stained with cresyl violet 1 and 3 months after injury (12-14 sections per brain, spanning approximately $3.0-0.0 \mathrm{~mm}$ bregma). The unbiased Cavalieri method was employed using StereoInvestigator software (MicroBrightField, Williston, Vt., USA), with a grid size of $150 \mu \mathrm{m}$ and a sampling interval of 6 . Measurements were confined to the dorsal ipsilateral and dorsal contralateral cortices, with the inferior boundary defined by a horizontal delineating the most ventromedial point of the corpus callosum. The Gundersen mean coefficient of error for individual estimates was maintained at $<0.05$. Group means are expressed as estimated volume (in cubic millimeters).

\section{Behavioral Tasks}

An extensive battery of behavioral assessments was performed in the order shown below, in two separate cohorts after sham operation and TBI, namely adolescent (p35-45) and adult mice (p70-80; $\mathrm{n}=$ 10 /group/time point). These time points correspond to brain development milestones and are in line with our previously characterized model of parietal lobe injury. Mice were housed singly and habituated to the testing room $24 \mathrm{~h}$ prior to commencement of testing. 'Stimulus' animals were naïve male $\mathrm{C} 57 \mathrm{Bl} / 6 \mathrm{~J}$ mice purchased at the same time and housed under identical conditions. Each 'test' mouse (TBI or sham) encountered a novel stimulus mouse once only.

\section{Rotarod}

The accelerating rotarod test was performed to assess general motor function and motor learning [16]. The latency to fall was recorded in seconds, and mice were tested across 3 consecutive days, 3 times per session, with an intersession interval of approximately $1 \mathrm{~h}$.
Open-Field Test

Exploratory behaviors were assessed over a 10-min session in an automated open-field arena (Kinder Scientific, Poway, Calif., USA), as previously described [16]. Interfaced Motor Monitor software calculated parameters, including distance traveled, rearing events and percentage of time spent in the central zone compared to the periphery.

\section{Elevated Plus Maze and Zero Mazes}

The elevated plus and zero mazes (Kinder Scientific) assess anxiety based upon the natural tendency of rodents to avoid the open arms of the maze in preference for enclosed areas [16]. For both tasks, mice were placed individually on the apparatus and allowed free access for $10 \mathrm{~min}$. Total distance moved and time spent in the open arms were assessed as previously described [16].

\section{Partition Test}

The test and stimulus mice were separated by a perforated platform, and the investigative time spent by the test mouse at the partition was quantified over a 5 -min period as previously described $[17,18]$.

\section{Tube Dominance}

In this task, test and stimulus mice were released simultaneously into opposite ends of a clear Plexiglas tube. Typically, one mouse will exert dominance and force the other to back out of the tube, which is thought to reflect a tendency for aggression [17]. This test was performed as previously described, using a $3.2-\mathrm{cm}$ diameter tube for adult mice and a $2.5-\mathrm{cm}$ tube for adolescents [18]. A win or loss and the trial duration were recorded and averaged across 3 trials.

\section{Resident-Intruder Task}

To further assess social investigative behaviors, a stimulus mouse was introduced into the established home cage of the test mouse, and investigative behaviors were quantified from video recordings as previously described $[18,19]$.

\section{Three-Chamber Task}

The 3-chamber paradigm allows for the evaluation of social affiliation and social recognition in mice $[18,20]$. In brief, three 10 min stages are conducted sequentially: stage 1 involves habituation in the apparatus; stage 2 is the addition of a stimulus mouse, as a test for sociability preferences, and stage 3 involves addition of a second novel stimulus mouse, as a test for social recognition based upon a preference for social novelty. Data were expressed as the time spent in each chamber (percentage of total time).

\section{Morris Water Maze}

The Morris water maze (MWM) was used to assess spatial learning and memory as previously described [16]. Mice underwent two daily sessions, consisting of three 60-second trials, for 5 consecutive days. During days 1 and 2, the platform was raised above the water surface and clearly labeled with a flag ('visible platform'). Mice that failed to reach the platform within $60 \mathrm{~s}$ were guided there by the investigator. During days 3, 4 and 5, the platform was submerged below the water surface ('hidden platform'), such that mice were required to use spatial cues from the room to locate it. The starting location was rotated for each trial. Movements were traced with an overhead mounted video camera inter- 
faced with Noldus EthoVision software, for quantification of distance, latency and velocity. At the conclusion of days 3, 4 and 5, the platform was removed from the pool and a 60-second 'probe trial' was conducted. A fourth probe trial, for long-term memory retention, was also performed 1 week later. The time spent in the target quadrant (where the platform was previously located) compared to the other quadrants was quantified.

\section{Buried Food Task}

As social behaviors in mice are predominantly mediated by olfactory cues [21], we lastly performed a buried food task to assess the ability of mice to detect a hidden volatile odor, as previously described $[18,22]$.

\section{Statistical Analysis}

Statistical analyses were performed using Prism GraphPad v5.0 (GraphPad Software, San Diego, Calif., USA), with a significance level of $\mathrm{p}<0.05$. Estimation of cortical volume was analyzed by 2 -way analysis of variance (ANOVA) and Bonferroni's post hoc tests as appropriate. Unpaired t tests or 2-way ANOVAs were used to compare sham and TBI mice in behavioral tasks, with repeated measures (RM) as appropriate, and factors of injury (TBI or sham) and either session or chamber. Results from post hoc analyses are stated as $\mathrm{p}<0.05, \mathrm{p}<0.01$ or $\mathrm{p}<0.001$ and annotated graphically. All data are expressed as means \pm SEM.

\section{Results}

Frontal TBI at p21 Results in Focal Hemorrhage and the Emergence of a Cortical Cavity

Apnea was either absent or very short-lived $(<3 \mathrm{~s})$ following impact to the frontal lobe. Both injured $(\mathrm{n}=36)$ and sham-operated $(\mathrm{n}=30)$ mice recovered from anesthesia without any mortality. Herniation of the brain through the craniotomy was evident immediately after impact. Prominent cortical hemorrhage was apparent at the site of impact $24 \mathrm{~h}$ after injury, which corresponded to a distinct cortical cavity at 7 days (fig. 1a, b). No macroscopic damage or hemorrhage was observed in the olfactory bulbs, contralateral hemisphere, brainstem, cerebellum or posterior fossa of either TBI or sham-operated mice. Body weight gains were similar between TBI and sham mice up to at least 3 months after surgery (2-way RM ANOVA: effect of injury, $\mathrm{F}_{1,18}=0.6537, \mathrm{p}=0.4293$; effect of time, $\mathrm{T}_{19,252}=1,247, \mathrm{p}<0.0001$ ).

\section{Traumatic Injury Results in Acute Cortical and \\ Subcortical Cell Injury}

FJC and TUNEL were used to evaluate cortical and subcortical patterns of cell injury (fig. 2a-c). FJC-positive cells were most prominent throughout the ipsilateral cortex and dorsal striatum $24 \mathrm{~h}$ after injury, as well as the ipsilateral corpus callosum (fig. 2a). Although decreased,
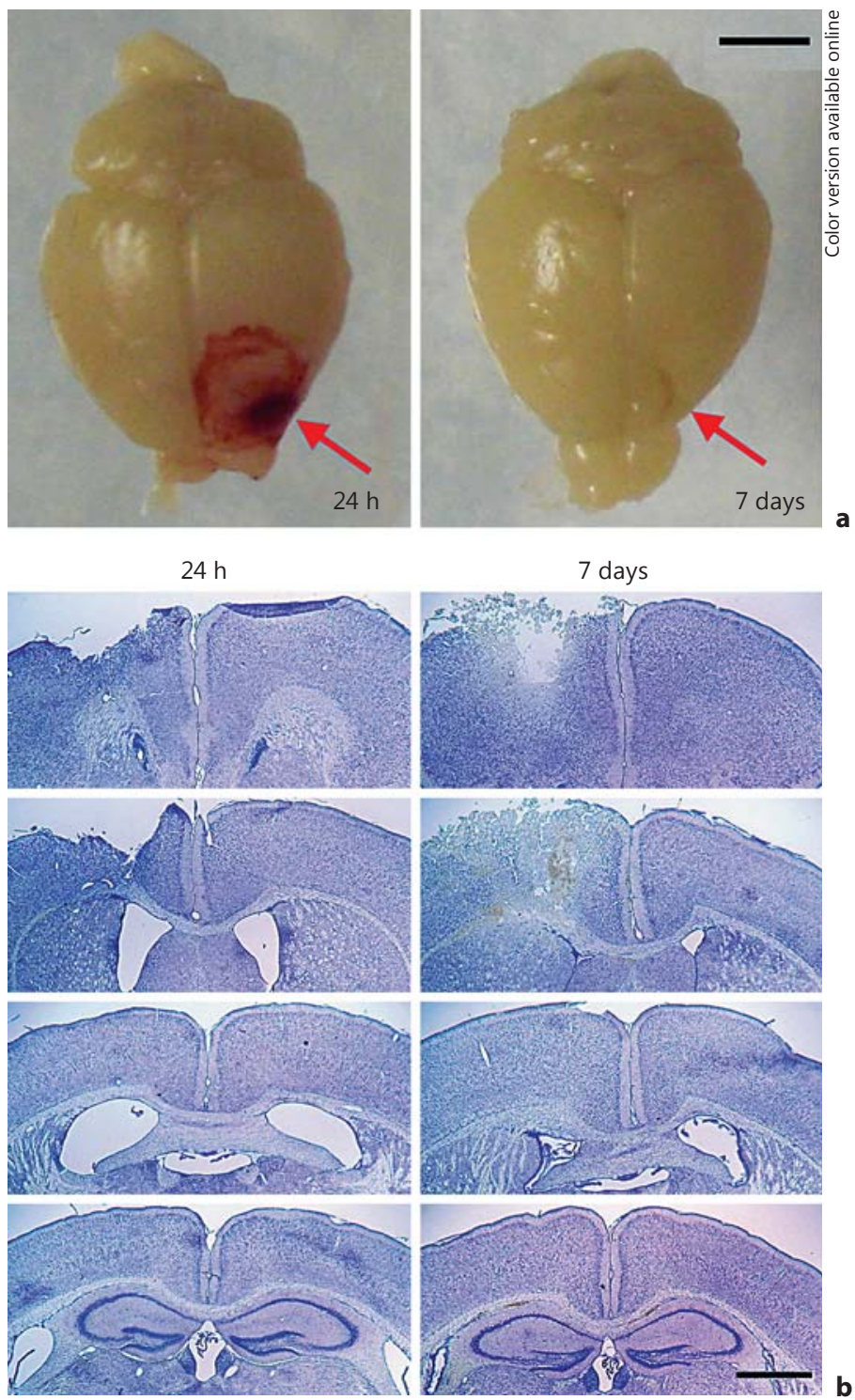

Fig. 1. Frontal TBI induces a distinct unilateral lesion. a Representative photographs of whole perfused brains collected $24 \mathrm{~h}$ and 7 days after injury (arrows indicate lesion site). Scale bar $=3 \mathrm{~mm}$. b Representative coronal sections stained with cresyl violet to delineate tissue damage at $24 \mathrm{~h}$ and 7 days. Images were captured at approximately $+1.70,+0.50,-0.10$ and $-0.15 \mathrm{~mm}$ from the bregma, respectively, from top to bottom.

modest labeling was still evident in the corpus callosum at 7 days (data not shown). TUNEL, which labels fragmented DNA of dead and dying cells, was also widespread $24 \mathrm{~h}$ after injury, with a distribution similar to that of FJC (fig. 2b). Abundant TUNEL-positive cells were evident in the ipsilateral cortex adjacent to the site of damage (fig. 2b), within the underlying corpus callosum, and 

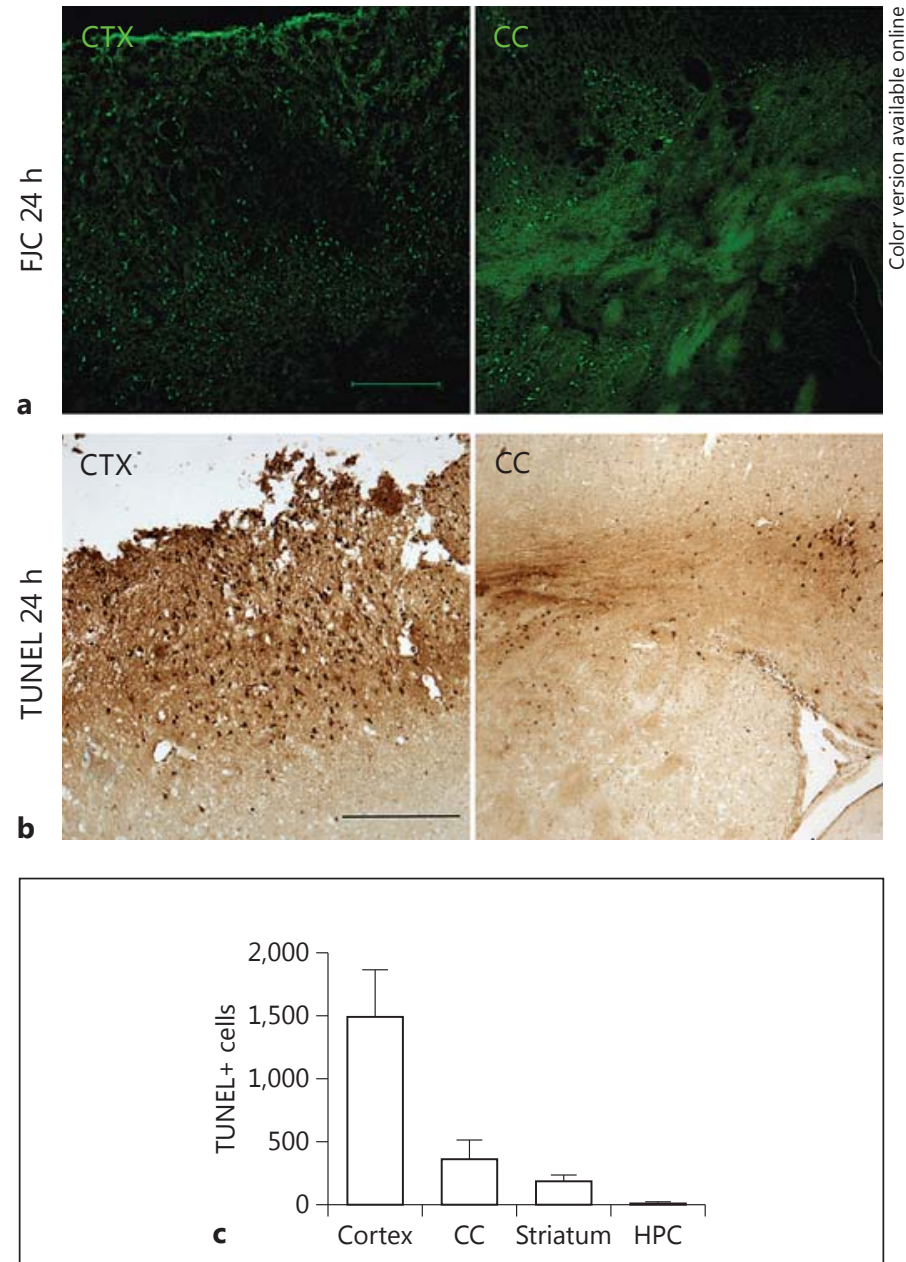

Fig. 2. Local cell death in the dorsal cortex and subcortical structures after frontal TBI. a Degenerating neurons were labeled with FJC $24 \mathrm{~h}$ after injury, revealing abundant neuronal damage in the pericontusional cortex (CTX) and dorsal striatum. Scale bar $=200$ $\mu \mathrm{m}$. b Cell death was confirmed by TUNEL staining, which was widespread in the pericontusional cortex as well as in the underlying corpus callosum (CC) and striatum. Scale bar $=250 \mu \mathrm{m}$. c TUNEL-positive cells were summed across 5 sections per brain $24 \mathrm{~h}$ after injury, highlighting the regional localization of acute cell death after frontal TBI (one-way ANOVA: $\mathrm{F}_{3,28}=11.07, \mathrm{p}<0.0001$; $\mathrm{n}=8$ ). Vertical bars represent the SEM. HPC $=$ Hippocampus.

in the dorsal striatum. Quantification in the ipsilateral hemisphere at $24 \mathrm{~h}$ supported these observations of region-dependent vulnerability (fig. 2c). We also examined the presence of activated (cleaved) caspase-3, a hallmark of apoptotic cell death, both $24 \mathrm{~h}$ and 7 days after injury, but found very few positive cells in the injured frontal cortex ( $<10 /$ brain; data not shown), suggesting a predominance of necrotic cell death at these times.

\section{Injury Results in Glial Changes That Persist into Adulthood}

Sham-operated brains contained widespread GFAPpositive astrocytes and low Iba-1 immunoreactivity (fig. 3a-h). At $24 \mathrm{~h}$ after injury, GFAP reactivity was more intense in the pericontusional area, and prominent cell processes were noted. By 7 days after injury, staining was robustly elevated over sham levels, particularly in the pericontusional parenchyma, and associated with a glial scar. GFAP-positive astrocytes persisted in the injured cortex until at least 3 months after injury. In contrast to the delayed astrocytic response that appeared to peak at 7 days, activated microglia and macrophages showed a robust increase in Iba-1 reactivity by $24 \mathrm{~h}$ after injury (fig. 3i-p). Iba-1-positive cells were most prominent in the dorsal cortex, corpus callosum and striatum by 7 days after injury, and intensely labeled Iba-1-positive cells were still evident 3 months after injury, although they appeared to be fewer in number.

\section{Traumatic Axonal Injury Is a Signature Feature of the \\ Injured Brain}

Traumatic axonal injury is a distinct pathological consequence of TBI which can be identified by the accumulation of $\beta$-APP in swollen axons [23]. There was no evidence of $\beta$-APP accumulation in sham animals (data not shown). At $24 \mathrm{~h}$ after injury, abundant $\beta$-APP-positive cells and swollen axons were found in the pericontusional dorsal cortex and corpus callosum (fig. $4 \mathrm{a}-\mathrm{c}$ ). Filamentous staining with a beaded appearance was evident in the ipsilateral corpus callosum beneath the lesion site, extending across the midline into the contralateral corpus callosum. At 7 days, the intensity of $\beta$-APP staining was considerably reduced (fig. $4 \mathrm{~d}, \mathrm{e}$ ), and the staining was mostly granular or globular in appearance. Minimal, localized immunoreactivity remained 1 month after injury, but no evidence of $\beta$-APP staining was found by 3 months (data not shown).

\section{Volumetric Reduction in the Injured Frontal Lobe}

Peaks 1 Month after Injury

Cresyl violet staining of brains collected 1 and 3 months after injury revealed the formation of a pronounced cortical cavity, ventricular enlargement and deformation of the ipsilateral corpus callosum (fig. 5a-c). At 1 month after injury, the ipsilateral dorsal cortex was significantly reduced compared to sham mice. In contrast, the contralateral cortex volume of sham and TBI mice was comparable (not significant on post hoc analysis). Ipsilateral tissue loss was similar at 3 months, with a significant volume reduction in the dorsal cortex in TBI 

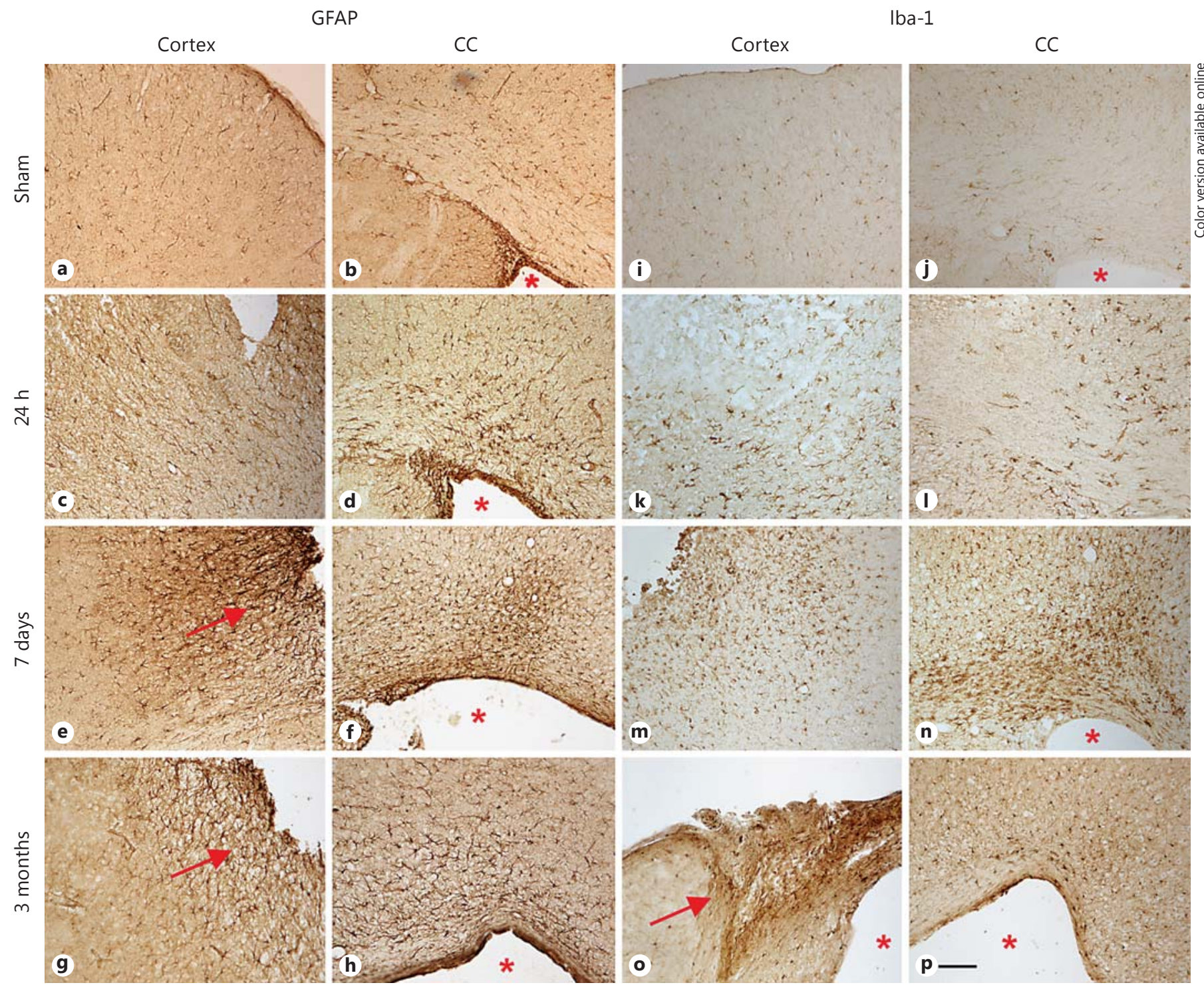

Fig. 3. Immunoreactivity for astrocytes (GFAP) and reactive microglia/macrophages (Iba-1) is evident in the ipsilateral dorsal cortex $(\mathbf{c}, \mathbf{e}, \mathbf{g}, \mathbf{k}, \mathbf{m}, \mathbf{o})$ and corpus callosum $(C C ; \mathbf{d}, \mathbf{f}, \mathbf{h}, \mathbf{j}, \mathbf{I}, \mathbf{n}, \mathbf{p})$ after frontal TBI. Sham operation did not induce gliosis at $24 \mathrm{~h} \mathrm{(a,} \mathrm{b,} \mathrm{i,}$ j). At $24 \mathrm{~h}$ after injury (c, d, $\mathbf{k}, \mathbf{I}$ ), only a few reactive astrocytes are noted, although Iba-1 reactivity was increased above sham levels. By 7 days (e, f, $\mathbf{m}, \mathbf{n})$, both GFAP+ astrocytes and Iba-1+-reactive

microglia were visibly accumulating in the pericontusional parenchyma. By 3 months after injury, GFAP+ astrocytes formed a glial scar at the cortical lesion edge $(\mathbf{g}, \mathbf{h})$. The lesion core (o) also stained strongly for Iba-1 at these times. Scale bar $=100 \mu \mathrm{m}$. Arrows indicate a glial scar; asterisks highlight the enlarged lateral ventricle.

mice compared to sham mice. The volume of the remaining ipsilateral dorsal cortex was strikingly comparable in brain-injured mice in adolescence and adulthood (7.67 \pm $0.47 \mathrm{~mm}^{3}$ at 1 month; $8.18 \pm 0.49 \mathrm{~mm}^{3}$ at 3 months; t test: $\left.\mathrm{t}_{18}=0.7482, \mathrm{p}=0.4640\right)$. No differences were found between cortical volumes in either hemisphere of sham-operated mice 1 or 3 months after surgery.

\section{Injury Results in Impairments in Motor Function in Adulthood}

The accelerating rotarod task was employed to evaluate motor function after frontal lobe injury (fig. 6a). Overall, the latency to fall increased over 3 consecutive days, with a significant effect of time in both adolescence (2-way RM ANOVA: $\left.\mathrm{F}_{2,36}=19.98, \mathrm{p}<0.0001\right)$ and adult- 
Fig. 4. Axonal degeneration was detected by immunostaining for $\beta$-APP accumulation after frontal TBI. a-c Immunopositive cells were abundant in the cortex (CTX) $24 \mathrm{~h}$ after injury $(\mathbf{a}, \mathbf{b})$, particularly in the pericontusional cortex (arrows). Filamentous staining was evident in the corpus callosum (CC) ipsilateral to the impact site $24 \mathrm{~h}$ after injury $(\mathbf{a}, \mathbf{c})$, indicating swollen or damaged axons in which $\beta$-APP was accumulating. This was most apparent directly ventral to the lesion site; however, immunoreactive axons were also evident crossing the midline into the contralateral corpus callosum (a). d, e At 7 days, much of the $\beta$-APP staining was granular or globular in appearance in the injured cortex and corpus callosum. Asterisks indicate the ipsilateral ventricle. Scale bar $=100 \mu \mathrm{m}$.
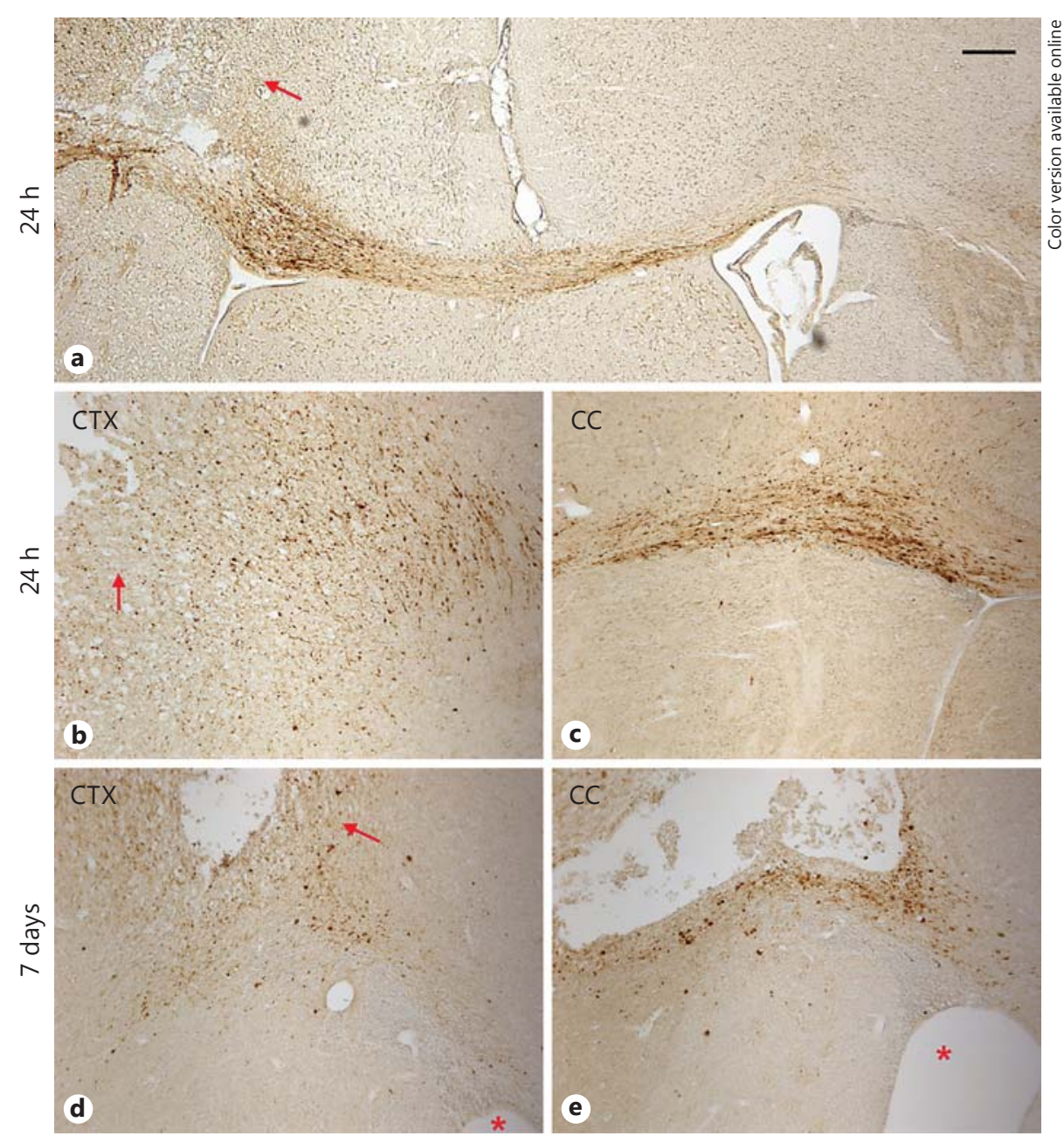

hood $\left(\mathrm{F}_{2,34}=11.18, \mathrm{p}=0.0002\right)$, indicating motor learning over time. In adolescence, TBI mice showed poorer performance across the testing period compared to sham mice (2-way RM ANOVA: effect of injury, $\mathrm{F}_{1,36}=20.77$, $\mathrm{p}=0.0002)$. Post hoc analyses found that sham and TBI mice performed similarly on day 1 , suggesting a comparable initial ability. However, while sham mice showed an increased mean latency on days 2 and 3, TBI mice failed to show this improvement (post hoc analysis: $\mathrm{p}<$ 0.001 and 0.05 on days 2 and 3, respectively). A similar pattern was evident in the adult cohort, which also showed a significant overall effect of injury (2-way RM ANOVA: $\left.\mathrm{F}_{2,34}=11.24, \mathrm{p}=0.0275\right)$. Again, TBI mice showed the greatest impairment on day 2 (post hoc analysis: $\mathrm{p}<0.05$ ), following performance comparable to that of sham animals on day 1 , suggestive of a deficit in motor learning.

\section{Reduced Rearing Behavior Emerges as Brain-Injured} Mice Reach Adulthood

Rearing behavior was evaluated in the open-field arena, as a measurement of forelimb motor function. In adolescence, sham and TBI mice spent an equivalent amount of time in an upright posture $\left(\mathrm{t}_{1,18}=0.3942, \mathrm{p}=0.6980\right.$; fig. $6 \mathrm{~b})$ and reared a comparable number of times $\left(\mathrm{t}_{1,18}=\right.$ $0.1678, p=0.8686$; data not shown). In contrast, adult TBI mice showed a significant deficit in rearing behavior, with a reduction in both the time spent rearing $\left(t_{1,17}=3.560\right.$, $\mathrm{p}=0.0024)$ as well as the number of occurrences $\left(\mathrm{t}_{1,17}=\right.$ $3.093, \mathrm{p}=0.0066$; data not shown). These findings indicate long-term motor impairment after frontal injury at a young age. 

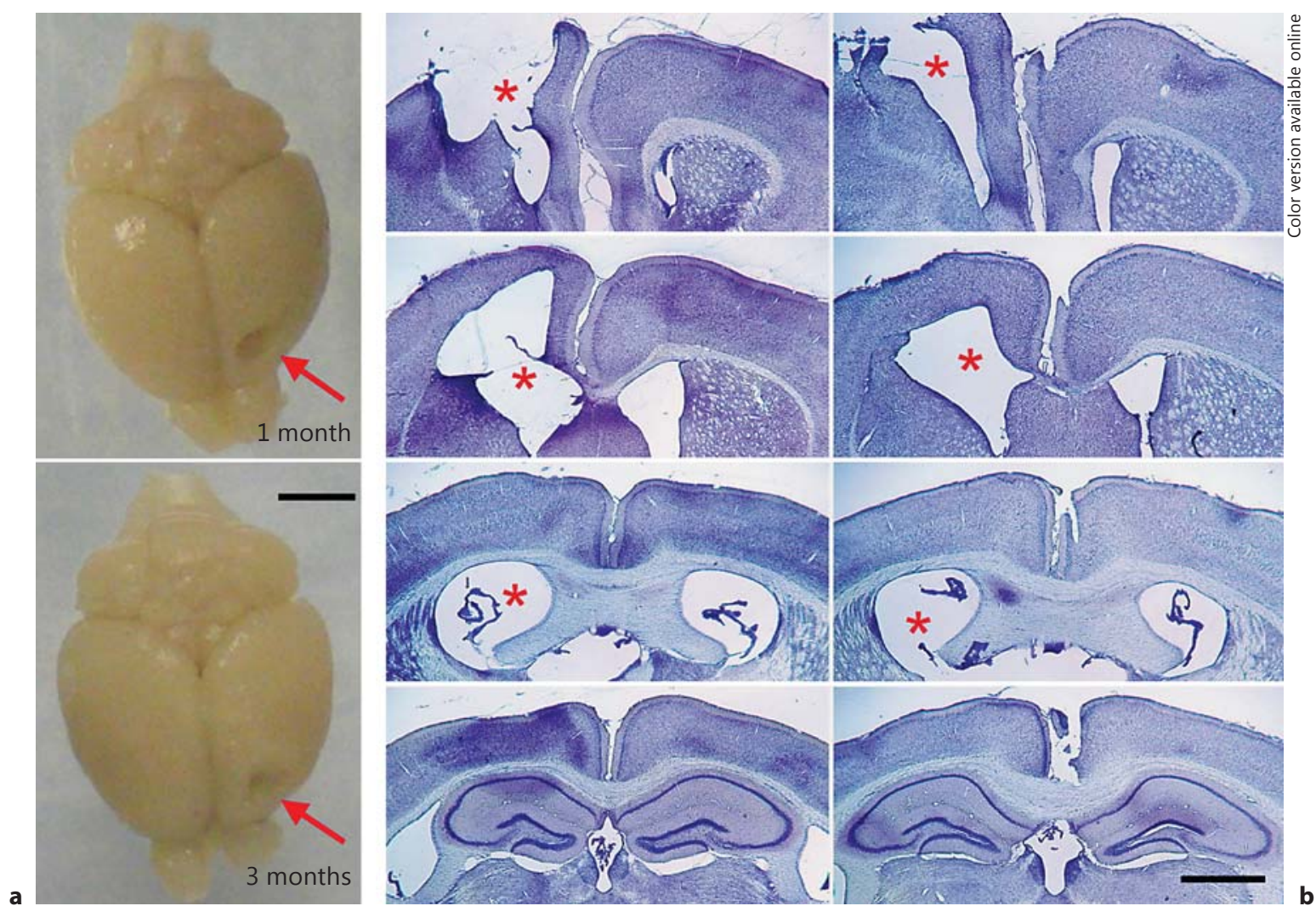

Fig. 5. Frontal TBI results in cavity formation and a volumetric reduction in the injured cortex. a, b At 1 and 3 months after injury, a pronounced unilateral cortical cavity was evident in whole perfused brains (arrows in a; scale bar $=3 \mathrm{~mm}$ ) and representative dorsal cortex sections stained with cresyl violet (b; scale bar $=500$ $\mu \mathrm{m})$. b Images were captured at approximately $+1.70,+0.50,-0.10$ and $-0.15 \mathrm{~mm}$ from the bregma, respectively, from top to bottom for each time point shown. Note the enlarged lateral ventricle ipsilateral to the injury site at 1 and 3 months (asterisks). c Remaining dorsal cortex was quantified at both 1 and 3 months after injury, demonstrating significant volumetric loss in the ipsilateral dorsal cortex at both time points. ${ }^{* * * *} \mathrm{p}<0.0001$ (post hoc 2 -way ANOVA; $\mathrm{n}=10$ /group).

\section{Assessments of Anxiety in Adolescent and Adult Mice} after Frontal TBI

The open-field test and elevated plus and elevated zero mazes were used to assess anxiety levels. The distance travelled was comparable between sham and TBI mice in all three tasks (data not shown). In the plus and zero mazes, anxiolytic behavior (measured as the time spent in the open area) was comparable between sham and TBI mice in both adolescence and adulthood. In the open-field task only, TBI mice showed an increase in

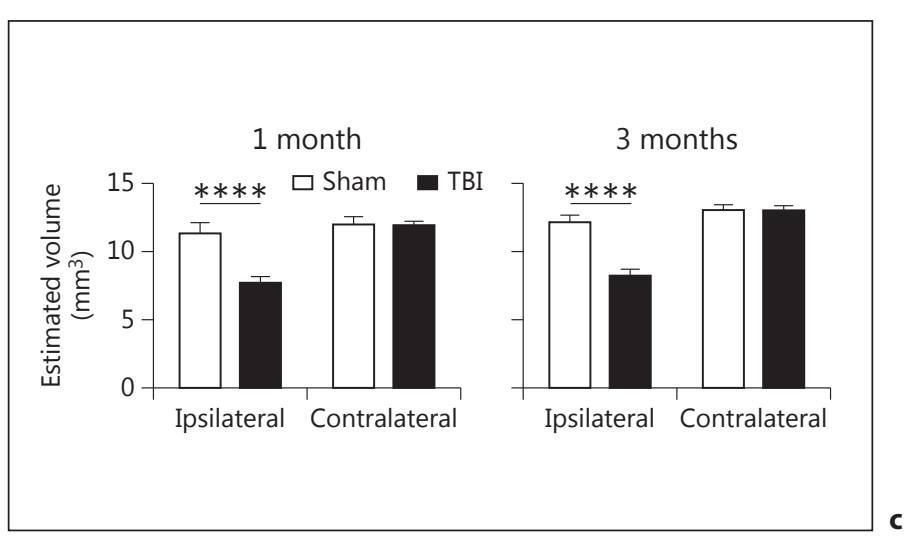

anxiety in adulthood but not in adolescence (online supplementary fig. 1; for all online suppl. material, see www. karger.com/doi/10.1159/000355874).

\section{Frontal Injury to the Immature Brain Does Not Alter \\ Social Investigation}

Social investigation was firstly assessed by the partition test (fig. 7a). There was no significant difference in the total investigative time spent at the partition between sham and TBI mice in either adolescence ( $t$ test: $t_{1,18}=$ 
Fig. 6. Motor learning and rearing deficits were evident after frontal TBI. a Mice were tested on the rotarod across 3 consecutive days. In adolescence, TBI mice showed a significant reduction in the mean latency to fall on days 2 and 3 (post hoc 2-way RM ANOVA: $\left.{ }^{*} \mathrm{p}<0.05,{ }^{* * *} \mathrm{p}<0.001\right)$ compared to sham-operated mice. Although less pronounced, this injury-dependent impairment was also evident in adulthood (post hoc analysis: ${ }^{*} \mathrm{p}<0.05$ ). b Rearing behavior measured in the open-field task was also used to detect forelimb motor function. While adolescent sham and TBI mice did not differ, adult TBI mice showed a significant deficit in rearing behavior compared to their respective shams, with a reduction in the time spent rearing $\left(t_{1,17}=3.560, p=0.0024 ; n=10\right.$ /group $)$. $* * \mathrm{p}<0.01$.
Adolescent
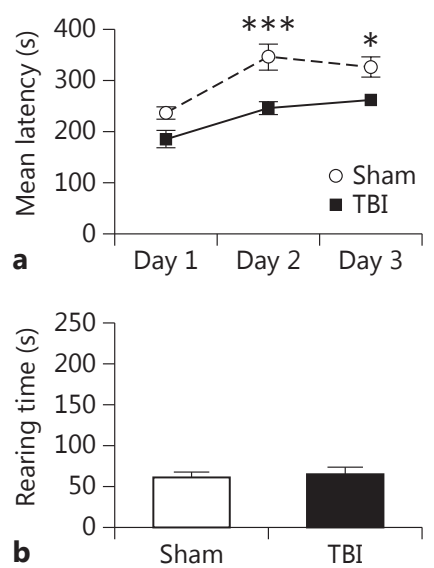

Adult
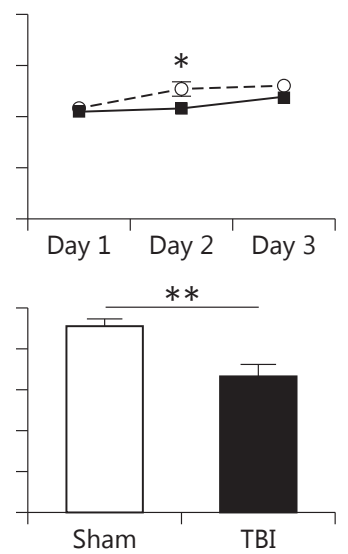

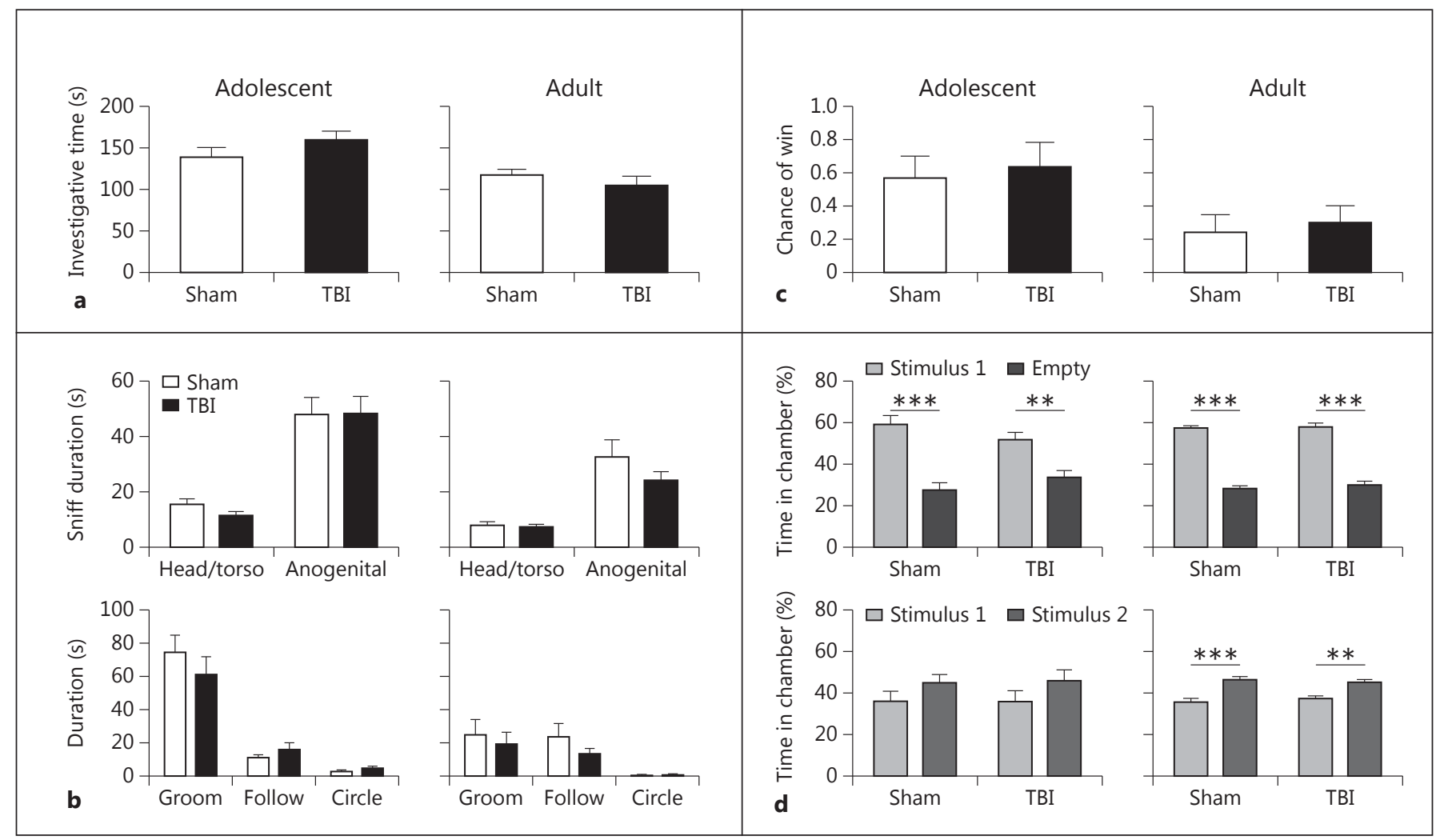

Fig. 7. Mice showed normal social function after frontal TBI. a The total investigative time in the partition task was similar in sham and TBI mice in both cohorts. $\mathbf{b}$ Several investigative behaviors in the resident-intruder test were quantified separately, including the time spent sniffing the head/torso or anogenital regions of the stimulus mouse and time engaged in grooming, following or circling behaviors. Sham and TBI mice showed equivalent investigative behaviors on all measures. c Performance on the tube domi- nance task, quantified as the chance of a 'win' by the test (sham or TBI) mouse, was also unaffected by injury. $\mathbf{d}$ The 3-chamber task was used to delineate a preference for sociability (stage 2: choice between stimulus 1 and empty chambers) and social novelty (stage 3: choice between stimulus 1 and 2). In both adolescence and adulthood, sham and TBI mice showed a similar preference for sociability and social novelty in these tasks ( $\mathrm{n}=10$ /group). ${ }^{* *} \mathrm{p}<$ $0.01,{ }^{* * *} \mathrm{p}<0.001$. 
Fig. 8. Spatial learning and memory were assessed in the MWM after frontal TBI. a The swimming speed of TBI mice in both adolescence and adulthood was reduced compared to sham animals (2-way RM ANOVA, effect of injury). b Despite this, brain-injured mice at adolescence were able to locate both the visible and hidden platforms similarly to sham-operated mice, with all mice showing learning over time. In adulthood, TBI mice showed a reduction in the distance taken to reach the visible platform during sessions 2 and 3 compared to sham mice (post hoc 2-way RM ANOVA: $\left.{ }^{*} \mathrm{p}<0.05,{ }^{* *} \mathrm{p}<0.01\right)$. However, sham and TBI mice showed equivalent performance during the hidden platform sessions. c, d Probe trials, in which the target platform is removed, were quantified as time spent in the target (black bars, indicated on schematic as the black quadrant containing the platform (circle)), opposite (white bars) or adjacent quadrants (gray bars) and were compared within each group (1-way ANOVA). Probe trials 1 and 2 are shown in supplementary figure 2 . c In probe trial 3, all groups independent of injury or age showed memory retention by a preference for the target quadrant. d Probe trial 4 was performed 1 week following probe trial 3. Regardless of injury, adolescent mice did not show a preference for the target quadrant, indicating a lack of longterm spatial memory. In the adult cohort, both sham and TBI mice showed longterm memory retention, with a strong preference for the target quadrant. ${ }^{*} \mathrm{p}<0.05$, ** $\mathrm{p}<0.01,{ }^{* * * *} \mathrm{p}<0.0001$ (post hoc analysis; $\mathrm{n}=10$ /group).
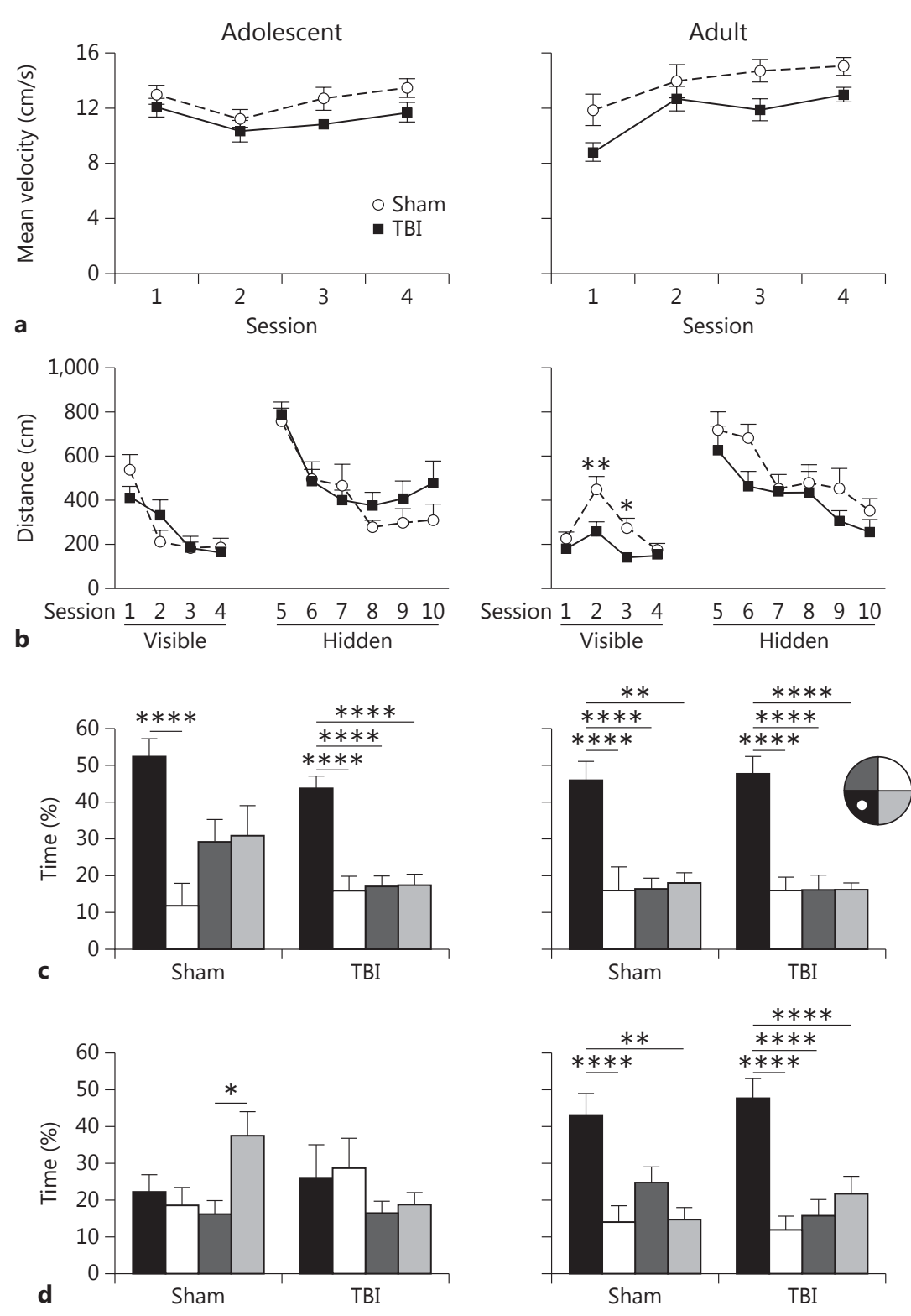

1.450, $\mathrm{p}=0.1644)$ or adulthood $\left(\mathrm{t}_{1,17}=0.9280, \mathrm{p}=\right.$ $0.3664)$. Similarly, in the complementary resident-intruder task (fig. 7b), sham and TBI mice showed comparable interest in the stimulus mouse (no effect of injury: $p=0.6934$ in adolescence, $p=0.1988$ in adulthood). In addition, injury did not affect engagement in other investigative behaviors in adolescence, including grooming $\left(\mathrm{t}_{1,18}=0.8884, \mathrm{p}=0.3861\right)$, following $\left(\mathrm{t}_{1,18}=1.018, \mathrm{p}=\right.$ $0.3222)$ or circling behaviors $\left(t_{1,18}=1.5559, \mathrm{p}=0.1364\right)$.
In adulthood, TBI and sham mice also spent comparable time grooming $\left(t_{1,17}=0.5099, p=0.6167\right)$, following $\left(\mathrm{t}_{1,17}=1.199, \mathrm{p}=0.2471\right)$ and circling the stimulus mouse $\left(t_{1,17}=0.3784, p=0.7098\right)$. Overall, both sham and TBI test mice spent significantly more time sniffing the anogenital region of the stimulus mouse compared to the head and torso (2-way ANOVA for effect of region: $\mathrm{F}_{1,36}=59.60, \mathrm{p}<0.0001$ in adolescence; $\mathrm{F}_{1,34}=$ $35.75, \mathrm{p}<0.0001$ in adulthood). 
Injury Does Not Alter Social Dominance, Sociability or Social Recognition

The tube dominance task was used to determine social dominance between the test mouse and a novel stimulus mouse, with the hypothesis that tendencies towards social dominance or aggression may be altered after injury. However, the likelihood of the test mouse winning its encounter was similar in both sham and TBI mice in the adolescent cohort (fig. $7 c ; t_{1,18}=0.3408, p=0.7372$ ). Adult mice also exhibited a comparable chance of winning their encounters, regardless of injury $\left(t_{1,17}=0.4270\right.$, $\mathrm{p}=0.6747)$.

We next evaluated preferences for sociability and social novelty using the 3-chamber task, as described previously (fig. $7 d$ ) $[18,20,24]$. Adolescent mice showed a normal preference for sociability, as evidenced by significantly more time spent in the chamber containing stimulus mouse 1 compared to the empty chamber (2way ANOVA: effect of chamber, $\mathrm{F}_{1,36}=50.81, \mathrm{p}<0.0001$ ). This was comparable in both sham and TBI mice (no effect of injury: $F_{1,36}=0.0306, p=0.8633$ ). When tested during adulthood, there was also a strong differential response to the stimulus mouse $\left(\mathrm{F}_{1,34}=274.6, \mathrm{p}<0.0001\right)$, which again was consistent regardless of injury $\left(\mathrm{F}_{1,34}=\right.$ $0.3455, \mathrm{p}=0.5606$ ). In the subsequent test stage, which evaluates a preference for social novelty, adolescent mice tended to spend more time in the chamber containing the new stimulus mouse 2 compared to stimulus mouse 1 ; however, this effect did not reach significance (effect of chamber: $F_{1,36}=3.347, p=0.0756$ ). When tested during adulthood, however, all mice showed a strong preference for social novelty (effect of chamber: $\mathrm{F}_{1,34}=33.96$, $\mathrm{p}<$ $0.0001)$. There was no effect of injury in either adolescence $\left(\mathrm{F}_{1,36}=0.007, \mathrm{p}=0.9339\right)$ or adulthood $\left(\mathrm{F}_{1,34}=\right.$ $0.008, \mathrm{p}=0.9281)$.

\section{Olfactory Function Is Normal after Injury to the} Frontal Lobe

Since olfactory cues are essential for social behaviors in mice [21], and frontal lobe injury in rodents may cause damage to the adjacent olfactory bulbs, we assessed olfactory function using a buried food task. We found no significant difference in the latency to find a buried food source in TBI mice compared to sham mice in either adolescence (sham vs. TBI: $55.8 \pm 18.5$ vs. 98.0 $\left.\pm 30.8 \mathrm{~s} ; \mathrm{t}_{1,18}=1.174, \mathrm{p}=0.2555\right)$ or adulthood ( vs. TBI: $175.1 \pm 36.6$ vs. $195.9 \pm 50.5$ s; $t_{1,17}=0.3269$, $\mathrm{p}=0.7477$ ), indicating comparable olfactory function regardless of injury.
Brain-Injured Mice Retain Normal Spatial Learning and Memory in the MWM

The MWM was used to assess cognitive function after frontal TBI. Firstly, the average velocity was quantified during sessions 1-4 as a measure of swimming speed and ability (fig. 8a). In adolescence, while there was an overall increase in velocity (2-way RM ANOVA: effect of time, $\mathrm{F}_{3,18}=4.064, \mathrm{p}=0.0112$ ), TBI mice showed a lower velocity across the testing period (effect of injury: $\mathrm{F}_{1,18}=4.554$, $\mathrm{p}=0.0469$ ). This was also evident in the adult cohort (effect of injury: $F_{1,17}=6.939, p=0.0174$; effect of time: $\mathrm{F}_{3,17}=12.020, \mathrm{p}<0.0001$ ), indicating that brain-injured mice show a swimming deficit in this task. As such differences may confound the latency to reach the platform, a commonly used outcome measure, we instead examined the distance travelled by mice to reach the platform [25].

In adolescence, all mice showed a steep learning curve in sessions 1-4 (fig. 8b), with a considerable reduction over time in the distance travelled to find the visible platform (2-way RM ANOVA: effect of time, $\mathrm{F}_{3,18}=19.92$, $\mathrm{p}<0.0001)$. However, there was no overall difference in performance between sham and TBI mice (effect of injury: $\left.F_{1,18}=0.019, p=0.8933\right)$. In the adult cohort, we expected to see a similar pattern of improvement in performance across the visible sessions; although this was indeed the case (2-way RM ANOVA: effect of time, $\left.\mathrm{F}_{3,17}=12.50, \mathrm{p}<0.0001\right)$, mice in session 1 showed an unusually short distance travelled, suggesting an artifact in the paradigm setup. Distinct from the adolescent cohort, in adulthood we saw an injury effect in this learning task (effect of injury: $F_{1,17}=10.62, p=0.0046$ ), with TBI mice actually travelling a shorter distance to find the platform compared to sham mice in sessions 2 and 3 (post hoc analysis: $\mathrm{p}<0.01$ and $\mathrm{p}<0.05$, respectively).

The hidden platform sessions (6-10) challenge mice to locate a submerged platform using external spatial cues. All mice showed an improvement in this task over time in both the adolescent (2-way RM ANOVA: effect of time, $\left.\mathrm{F}_{5,18}=9.873, \mathrm{p}<0.0001\right)$ and adult cohorts $\left(\mathrm{F}_{5,17}=4.729\right.$, $\mathrm{p}<0.0001)$. However, performance was similar between TBI and sham groups at both ages (effect of injury: $\mathrm{F}_{5,18}=3.899, \mathrm{p}=0.1935$ in adolescence; $\mathrm{F}_{5,17}=0.019$, $\mathrm{p}=0.1468$ in adulthood).

Probe trials provide a measure of memory retention by quantifying the time spent in the target quadrant (with the platform now removed) compared to the other quadrants. In the adolescent cohort, both sham and TBI mice spent equivalent time in all four quadrants during the first probe trial, with a preference for the target quadrant emerging by probe trial 2 (online suppl. fig. 2). By probe 
trial 3 (fig. 8c), both sham and TBI adolescent mice show a strong preference for the target quadrant compared to the other quadrants $\left(\mathrm{F}_{3,36}=6.776, \mathrm{p}=0.0001\right.$, and $\mathrm{F}_{3,36}=$ $16.66, \mathrm{p}<0.0001$, respectively; post hoc analysis as shown on fig. 8c). Interestingly, this preference was lost by probe trial 4 (1 week later; fig. $8 \mathrm{~d}$ ), suggesting that adolescent mice fail to retain this spatial memory long-term. In the adult cohort, all mice demonstrated improvements in this task between probe trials 1 and 2 (online suppl. fig. 2). By probe trial 3 (fig. $8 \mathrm{c}$ ), both sham and TBI adult mice showed a strong preference for the target quadrant $\left(\mathrm{F}_{3,32}=9.813, \mathrm{p}<0.0001\right.$ for sham mice; $\mathrm{F}_{3,36}=16.99, \mathrm{p}<$ 0.0001 for TBI mice). In contrast to the adolescent cohort, adult sham animals showed a similar preference for the target quadrant 1 week later in probe trial 4 (fig. 8d; $\left.\mathrm{F}_{3,32}=8.056, \mathrm{p}=0.0004\right)$, which was also comparable in TBI mice $\left(\mathrm{F}_{3,36}=12.86, \mathrm{p}<0.0001\right)$.

\section{Age-Dependent Behavioral Phenotypes in Locomotor} Activity and Social Investigation

The aforementioned analyses were all performed comparing sham and TBI mice at each age separately, as per the study design, to gauge the impact of brain injury within each cohort. During data analysis, however, it became apparent that age-dependent phenotypes existed, independent of injury. Thus, we examined, by means of 2-way ANOVAs with factors of age and injury, whether adolescent and adult mice exhibit different behavioral phenotypes. In the open-field paradigm, we found a significant effect of age on the distance moved $\left(\mathrm{F}_{1,35}=29.67\right.$, $\mathrm{p}<$ 0.0001 ), reflecting an increase in general locomotion by adult mice compared to adolescents (online suppl. fig. 1a). In the elevated plus and zero mazes (online suppl. fig. 1b), we also saw a greater distance traveled by adult mice compared to adolescent mice $\left(\mathrm{F}_{1,35}=179.9, \mathrm{p}<0.0001\right.$, and $\mathrm{F}_{1,35}=29.03, \mathrm{p}<0.0001$, respectively). There was no effect of injury on distance moved in any of these tasks ( $p=$ $0.1917,0.239$ and 0.3878 , for the open-field test and plus and zero mazes, respectively). We also saw that adult mice reared more often than adolescent mice in the open field $\left(\mathrm{F}_{1,36}=72.16, \mathrm{p}<0.0001\right)$ and spent more time upright $\left(\mathrm{F}_{1,36}=146.6, \mathrm{p}<0.0001\right.$; fig. 5b). Thus, adult mice showed an overall higher level of activity and locomotion compared to adolescent mice.

In contrast, an age-dependent reduction in social behaviors was consistently detected with increasing age. Independent of injury, the adult cohort showed reduced investigative time in the partition test (fig. $6 a ; F_{1,35}=16.43$, $\mathrm{p}=0.0003$ ), as well as in the resident-intruder test (fig. 6b; $\left.\mathrm{F}_{1,36}=19.74 ; \mathrm{p}<0.0001\right)$, compared to adolescent mice.

Frontal Traumatic Injury to the Developing Brain
The tube dominance task also revealed an unexpected effect of age, where adult mice had a lower chance of winning their encounter (fig. $6 c ; F_{1,35}=7.408, p=0.0101$ ) compared to adolescent animals. Together, these observations are consistent with previous observations that juvenile animals show high sociability.

Lastly, we revealed an interesting age-dependent finding in the final probe trial of the MWM (fig. 7d). Independent of injury, adult mice showed a strong preference for the target quadrant compared to the opposite and adjacent quadrants, indicating long-term memory retention. In contrast, adolescent mice did not favor the target quadrant over any other at this time, suggesting that they were unable to retain spatial memory long-term.

\section{Discussion}

This is the first comprehensive anatomical and behavioral assessment of traumatic injury to the developing frontal cortex. We described patterns of cortical and subcortical cell loss and axonal degeneration, determined the extent to which injury at an early age influences longterm volumetric changes in the cortex and profiled specific changes in the behavioral repertoire that are unique to this model. Lastly, we identified age-dependent behavioral phenotypes that are independent of injury.

\section{Injury to the Frontal Lobe: From Early Necrosis to \\ Long-Term Volumetric Loss}

This model produces acute intracranial bleeding and swelling of the impacted cortex as well as robust cell death in the pericontusional cortex and underlying subcortical structures, as indicated by abundant FJC and TUNEL staining $24 \mathrm{~h}$ and 7 days after injury. The accumulation of $\beta$-APP within pericontusional and contralateral white matter tracts is consistent with traumatic axonal degeneration, another hallmark of brain injury [23]. A prominent glial response was also evident across the first week following injury, with an earlier increase in Iba- $1 \mathrm{immu}-$ noreactivity compared to GFAP-positive astrocytes. By 1 and 3 months after frontal TBI, a pronounced cavity was observed in the ipsilateral dorsal cortex which merged with an enlarged lateral ventricle anteriorly. Interestingly, the extent of tissue loss by volumetric analysis was strikingly similar at both 1 and 3 months after injury, suggesting that the lesion had stabilized by 1 month. This is in contrast to our previously characterized model of parietal lobe CCI in p21 mice, in which the cortical lesion expands in parallel with brain maturation from day 7 to 14 [26] 
and from adolescence to adulthood [16], suggestive of ongoing neurodegeneration over a longer time period.

Frontal contusions, encephalomalacia and thinning of the frontal cortices are particularly common after TBI in children $[6,27,28]$. Upon autopsy, axonal injury as evidenced by $\beta$-APP accumulation is characteristic of braininjured infants and young children [23], consistent with evidence of widespread damage to white matter tracts detected by diffusion tensor imaging [27, 29]. The clinical importance of such damage is emphasized by findings that extensive frontotemporal atrophy $2-3$ years after moderate-to-severe TBI in children is associated with poorer functional recovery [9]. Our new model, which features acute traumatic axonal damage and pronounced volumetric loss of the frontal lobe, thus replicates many of the pathological findings associated with TBI to the frontal lobes in children.

\section{Persistent Motor Impairment after Unilateral Frontal TBI}

Functional outcomes were assessed in adolescence and early adulthood, based upon previous studies in both rodents and monkeys demonstrating that significant impairments may not emerge until later in life $[16,30,31]$. Here, we found cortical damage and overt tissue loss in the M1, M2 and supplementary motor cortex, regions which are essential for the planning, coordination and execution of movements [32]. Not surprisingly, the presence of distinct deficits in motor function/learning, evidenced by poor rotarod performance as well as a slower swimming speed and reduced rearing, was a salient functional outcome of this injury model. Importantly, these deficits persist into adulthood, suggesting that any compensatory mechanisms in the developing brain are inadequate to overcome region-specific cortical damage. Impairments in gait, reaching and grasping movements, balance, fine motor skills and coordination are reported after brain injury in school-aged children [33-35] and adults [36-38]. However, there is still a scarcity of data regarding motor function in younger, toddler-aged children after TBI, and whether such functional impairments persist or improve over time. Our new model has great potential for the exploration of the underlying mechanisms and potential interventions for injury-dependent motor dysfunction. Future studies utilizing forelimb-specific tasks or detailed gait analyses may be useful to delineate laterality and fine motor components of these impairments, particularly in the context of testing novel therapeutics or interventions which may have a functional benefit for the injured developing brain.
Table 1. Pathological and functional consequences of unilateral injury to the parietal versus frontal lobe in the p21 mouse

\begin{tabular}{lll}
\hline Pathology/behavior & $\begin{array}{l}\text { Parietal } \\
\text { injury }\end{array}$ & $\begin{array}{l}\text { Frontal } \\
\text { injury }\end{array}$ \\
\hline Cell death and neuronal loss & + & + \\
$\quad$ Frontal cortex & - & + \\
$\quad$ Parietal cortex & + & - \\
$\quad$ Hippocampus & + & - \\
$\quad$ Dorsal striatum & - & + \\
$\quad$ Dorsal thalamus & + & - \\
Anterior corpus callosum & - & + \\
$\quad$ Posterior corpus callosum & + & - \\
Reactive gliosis & + & + \\
Axonal injury & + & + \\
Hyperactivity & + & - \\
Memory deficits & + & - \\
Social deficits & + & - \\
Anxiety & $+/-$ & - \\
Motor deficits & - & + \\
\hline
\end{tabular}

\section{Regional Specificity of Functional Outcomes}

In contrast to significant motor impairment, there was no evidence that injury to the frontal cortex altered anxiety levels, social behavior or spatial memory performance. Moreover, there was preservation of normal spatial learning and memory in the hippocampal-mediated MWM task in both adolescence and adulthood, consistent with a lack of pathology in the hippocampus. Such findings are in contrast to our previously characterized model of unilateral injury to the parietal cortex, in which social behaviors, spatial learning and memory are impaired but motor function is unaffected $[15,16]$. Comparison of these two models provides insight into the mechanisms and consequences of early-life TBI to different neuroanatomical regions (table 1).

It is important to place our behavior findings in the broader context of other studies that have addressed CCI to the developing rodent brain. Rats with injury to the unilateral parietal lobe at p7, p17 and p28 show spatial learning and memory deficits in the MWM [39-41], which persist up to 3 months [42] and coincide with transient sensorimotor symptoms. Injury to the unilateral somatosensory cortex in p17 rats results in deficits on the rotarod task which persisted to 2 months after injury, as well as changes in anxiety which emerged at adulthood [43]. In contrast, the phenotype described herein, of pronounced and persistent motor deficits coexisting with normal cognitive function, is distinct from all existing ro- 
dent models of TBI at a young age. This model provides a unique opportunity to understand the mechanisms underlying these deficits as well as investigate functional recovery and potential compensation at both the brain and spinal cord level.

Does Early Frontal TBI Affect Anxiety in Adulthood?

Exploratory and anxiety-related behaviors were assessed in mice after frontal TBI. Here, we report a testspecific response, where adult TBI mice spent reduced time in the center of the open field compared to sham controls (suggestive of increased anxiety; online suppl. fig. 1a), in contrast to no differences in the elevated plus and zero mazes. While such a battery of tests may provide a more comprehensive understanding, the extent to which these tasks are related remains contentious [44, 45]. Use of the open-field paradigm as the sole measure of anxiety has been questioned, as performance on this task may be influenced by numerous factors including motor output, motivation, fear-related freezing, sickness and stress [44]. Given our findings, we conclude that frontal TBI at this magnitude of injury does not overtly alter anxiety. Future studies may incorporate measures of autonomic nervous system function, such as changes in heart rate, to correlate with findings from behavioral measures of anxiety [46].

\section{Normal Psychosocial Function after Unilateral \\ Frontal TBI to the Immature Brain}

Based upon the clinical literature indicating an adverse association between frontal lobe injury and psychosocial outcomes in brain-injured children [6], as well as our recent work identifying social deficits in adult mice after parietal lobe TBI at p21 [18], we hypothesized that unilateral frontal TBI at p21 would also result in notable social dysfunction. Contrary to expectations, however, brain-injured mice in this study were indistinguishable from sham controls on a battery of social behavior tests. One possible explanation for this finding is that the functional consequences of frontal injury are influenced by the age at insult. Developmental age is a strong predictor of outcome after early-life brain injury, as determined by both lesion experiments in rodents [47] and studies of young brain-injured patients $[48,49]$. It is widely accepted that the developing brain is less functionally specific than the mature brain, such that the establishment of regional localization of function is not yet complete. As a result, injury to the immature brain may trigger a more generalized dysfunction or, inversely, allow for the adaption of new neuronal networks to compensate for dam- age [50]. Developmentally regulated processes such as myelination and synaptic pruning are likely to contribute to and potentially modify injury mechanisms and functional consequences after TBI [51]. Evidence from other rodent studies supports this hypothesis of age-dependent vulnerability to frontal injury. Aspiration of the entire frontal lobe in rodents prior to $\mathrm{p} 6$ has been associated with a poorer behavioral outcome compared to a similar injury during the second or third week of life, when significant recovery was observed despite pronounced tissue loss $[47,52]$. It is possible that, at $\mathrm{p} 21$, the frontal lobe shows robustness to focal injury compared to TBI at earlier or later ages, such that there is functional recovery or compensation in terms of psychosocial behaviors. Investigation of unilateral frontal TBI at a range of different developmental ages will thus help to further elucidate regional and age-dependent specificity of social behaviors.

Secondly, the lack of psychosocial dysfunction in this model may be a consequence of lesion laterality. Here, we establish a unilateral injury to allow for direct comparison to our well-characterized unilateral parietal lobe injury model, also performed at p21 $[15,16]$ (table 1). Specific lesions to the anterior cingulate cortex reduce social interactions and social memory in rodents [53], and frontal lesions that alter social behavior in patients tend to extend from the orbitofrontal cortex medially into the anterior cingulate cortex [54]. In our current unilateral injury model, medial neuroanatomical structures are somewhat spared primary injury, which may explain preservation of social function in these mice. It is worth noting that the detailed assessment of social behaviors is not common after experimental TBI, such that the social consequences of bilateral frontal TBI to either the immature or adult brain are unknown.

Lastly, it is possible that functional consequences persist in this model of frontal TBI to the developing brain which have not yet been exposed. Problems with attention and orientation have been reported after bilateral frontal injury in adult rats [10], while a recent study demonstrated decision-making deficits using a new scent discrimination task which was specific to frontal injury [55]. Future studies are required to challenge young brain-injured mice with tasks that directly require frontal lobe input, to examine additional behaviors which are often impaired in young patients such as executive function, impulsivity, attention and inhibitory control $[48,56,57]$. 


\section{Age-Dependent Behaviors}

In line with several previous studies reporting the emergence of injury-induced impairments over the course of brain development $[16,30,31]$, we saw an agedependent emergence of rearing deficits, which were $a b-$ sent in adolescence but pronounced in adult brain-injured mice. We also uncovered a distinct effect of age on normal behavioral phenotypes, independent of injury. Adolescent mice demonstrated heightened social investigation compared to adult mice, consistent with adolescence being a time characterized by increased sociability $[58,59]$. This age-dependent behavior continues to decline with increasing age, as 30-month-old rats reportedly spend approximately $75 \%$ less time interacting socially compared to young adults [60]. In contrast, the distance traveled in the open-field test and plus and zero mazes showed an increase with age from adolescence to adulthood, suggestive of increasing exploratory behavior with maturation. Further, adolescent mice were unable to remember the location of the MWM platform during the final probe trial, suggesting that spatial memory retention is not fully developed at this age compared to in adult animals, consistent with a developmentally regulated improvement in spatial memory as reported in rats [61] and children [62]. Together, these data highlight the importance of using age-matched control animals in experiments across developmental time. Further characterization of the emergence of age-dependent behaviors may improve our understanding of the functional consequences of injury at different ages.

\section{Conclusions}

Brain injury during early life disrupts brain development and results in regionally specific consequences that persist into adulthood. Injury to the frontal lobes is particularly common in young brain-injured patients and associated with adverse outcomes. Here, we have developed a new model of unilateral frontal TBI to the immature mouse brain. Based on consistent findings of region-specific cellular vulnerability, coupled with evidence of a clinically relevant motor impairment, this model provides a unique opportunity to explore a phenotype of injury-induced motor dysfunction which persists into adulthood in the absence of detectable psychosocial or cognitive deficits. This model has applications both in the investigation of underlying mechanisms of functional deficits as well as the elucidation of age- and region-specific consequences of TBI. The development of interventions which target these motor deficits either acutely or chronically after injury has clinical applicability to young brain-injured patients in whom sensorimotor dysfunction persists.

\section{Acknowledgements}

The authors acknowledge the use of the Neurobehavioral Core of the University of California, San Francisco, and would like to thank the manager of this core, Sandra Canchola, for her assistance.

Funding was provided by National Institutes of Health/National Institute of Neurological Disorders and Stroke grants R01 NS050159 and NS077767 (L.J.N.-H.), a Sir Keith Murdoch Postdoctoral Fellowship from the American Australian Association (B.D.S.) and a CJ Martin Overseas Biomedical Postdoctoral Fellowship from the National Health and Medical Research Council of Australia (B.D.S.).

\section{References}

1 Langlois JA: Traumatic Brain Injury in the United States: Assessing Outcomes in Children. Atlanta, National Center for Injury Prevention and Control, 2000. http://www.cdc gov/traumaticbraininjury/pdf/TBI_assessing.pdf.

2 Claus CP, Tsuru-Aoyagi K, Adwanikar H, Walker B, Manvelyan H, Whetstone W, Noble-Haeusslein LJ: Age is a determinant of leukocyte infiltration and loss of cortical volume after traumatic brain injury. Dev Neurosci 2010;32:454-465.
- 3 Potts MB, Koh SE, Whetstone WD, Walker BA, Yoneyama T, Claus CP, Manvelyan HM, Noble-Haeusslein LJ: Traumatic injury to the immature brain: inflammation, oxidative injury, and iron-mediated damage as potential therapeutic targets. NeuroReport 2006;3: 143-153.

-4 Tsuru-Aoyagi K, Potts MB, Trivedi A, Pfankuch T, Raber J, Wendland M, Claus CP, Koh SE, Ferriero D, Noble-Haeusslein LJ: Glutathione peroxidase activity modulates recovery in the injured immature brain. Ann Neurol 2009;65:540-549.

5 Anderson V, Godfrey C, Rosenfeld JV, Catroppa C: 10 years outcome from childhood traumatic brain injury. Int J Dev Neurosci 2012;30:217-224.
6 6 Levin HS, Zhang L, Dennis M, Ewing-Cobbs L, Schachar R, Max J, Landis JA, Roberson G, Scheibel RS, Miller DL, Hunter JV: Psychosocial outcome of TBI in children with unilateral frontal lesions. J Int Neuropsychol Soc 2004;10:305-316.

7 Anderson V, Jacobs R, Harvey AS: Prefrontal lesions and attentional skills in childhood. J Int Neuropsychol Soc 2005;11:817-831.

-8 Eslinger PJ, Biddle KR: Adolescent neuropsychological development after early right prefrontal cortex damage. Dev Neuropsychol 2000;18:297-329. 
-9 Wilde EA, Hunter JV, Newsome MR, Scheibel RS, Bigler ED, Johnson JL, Fearing MA, Cleavinger HB, Li X, Swank PR, Pedroza C, Roberson GS, Bachevalier J, Levin HS: Frontal and temporal morphometric findings on MRI in children after moderate to severe traumatic brain injury. J Neurotrauma 2005;22:333-344.

$\checkmark 10$ Lindner MD, Plone MA, Cain CK, Frydel B, Francis JM, Emerich DF, Sutton RL: Dissociable long-term cognitive deficits after frontal versus sensorimotor cortical contusions. J Neurotrauma 1998;15:199-216.

11 Hoane MR, Lasley LA, Akstulewicz SL: Middle age increases tissue vulnerability and impairs sensorimotor and cognitive recovery following traumatic brain injury in the rat. Behav Brain Res 2004;153:189-197.

-12 Bravo TP, Matchett GA, Jadhav V, Martin $\mathrm{RD}$, Jourdain A, Colohan A, Zhang JH, Tang $\mathrm{J}$ : Role of histamine in brain protection in surgical brain injury in mice. Brain Res 2008; 1205:100-107.

13 Jadhav V, Matchett G, Hsu FP, Zhang JH: Inhibition of Src tyrosine kinase and effect on outcomes in a new in vivo model of surgically induced brain injury. J Neurosurg 2007;106: 680-686.

14 Kilbourne M, Kuehn R, Tosun C, Caridi J, Keledjian K, Bochicchio G, Scalea T, Gerzanich V, Simard JM: Novel model of frontal impact closed head injury in the rat. J Neurotrauma 2009;26:2233-2243.

-15 Tong W, Igarashi T, Ferriero DM, Noble LJ: Traumatic brain injury in the immature mouse brain: characterization of regional vulnerability. Exp Neurol 2002;176:105-116.

-16 Pullela R, Raber J, Pfankuch T, Ferriero DM, Claus CP, Koh SE, Yamauchi T, Rola R, Fike JR, Noble-Haeusslein LJ: Traumatic injury to the immature brain results in progressive neuronal loss, hyperactivity and delayed cognitive impairments. Dev Neurosci 2006;28: 396-409.

-17 Spencer CM, Alekseyenko O, Serysheva E, Yuva-Paylor LA, Paylor R: Altered anxietyrelated and social behaviors in the Fmrl knockout mouse model of fragile $\mathrm{X}$ syndrome. Genes Brain Behav 2005;4:420-430.

-18 Semple BD, Canchola SA, Noble-Haeusslein LJ: Deficits in social behavior emerge during development after pediatric traumatic brain injury in mice. J Neurotrauma 2012;29:26722683.

-19 Duvoisin RM, Villasana L, Davis MJ, Winder DG, Raber J: Opposing roles of mGluR8 in measures of anxiety involving non-social and social challenges. Behav Brain Res 2011;221: 50-54.

20 Yang M, Silverman JL, Crawley JN: Automated three-chambered social approach task for mice. Curr Protoc Neurosci 2011; chapter 8:unit 8.26.

-21 Ryan BC, Young NB, Moy SS, Crawley JN: Olfactory cues are sufficient to elicit social approach behaviors but not social transmission of food preference in C57BL/6J mice. Behav Brain Res 2008;193:235-242.
22 Yang M, Crawley JN: Simple behavioral assessment of mouse olfaction. Curr Protoc Neurosci 2009; chapter 8:unit 8.24.

23 Johnson VE, Stewart W, Smith DH: Axonal pathology in traumatic brain injury. Exp Neurol 2012;246:35-43.

24 Moy SS, Nadler JJ, Perez A, Barbaro RP, Johns JM, Magnuson TR, Piven J, Crawley JN: Sociability and preference for social novelty in five inbred strains: an approach to assess autistic-like behavior in mice. Genes Brain Behav 2004;3:287-302.

25 Gerlai R: Behavioral tests of hippocampal function: simple paradigms, complex problems. Behav Brain Res 2001;125:269-277.

26 Yoneyama-Sarnecky T, Olivas AD, Azari S, Ferriero DM, Manvelyan HM, NobleHaeusslein LJ: Heme oxygenase-2 modulates early pathogenesis after traumatic injury to the immature brain. Dev Neurosci 2010;32: $81-90$.

27 Oni MB, Wilde EA, Bigler ED, McCauley SR, Wu TC, Yallampalli R, Chu Z, Li X, Hunter JV, Vasquez AC, Levin HS: Diffusion tensor imaging analysis of frontal lobes in pediatric traumatic brain injury. J Child Neurol 2010; 25:976-984.

28 Wilde EA, Merkley TL, Bigler ED, Max JE, Schmidt AT, Ayoub KW, McCauley SR, Hunter JV, Hanten G, Li X, Chu ZD, Levin HS: Longitudinal changes in cortical thickness in children after traumatic brain injury and their relation to behavioral regulation and emotional control. Int J Dev Neurosci 2012;30:267-276

29 Wilde EA, Ayoub KW, Bigler ED, Chu ZD, Hunter JV, Wu TC, McCauley SR, Levin HS: Diffusion tensor imaging in moderate-to-severe pediatric traumatic brain injury: changes within an 18 month post-injury interval. Brain Imaging Behav 2012;6:404-416.

- 30 Kolb B, Whishaw IQ: Neonatal frontal lesions in hamsters impair species-typical behaviors and reduce brain weight and neocortical thickness. Behav Neurosci 1985;99:691-706.

31 Goldman PS: Functional recovery after lesions of the nervous systems. 3. Developmental processes in neural plasticity. Recovery of function after CNS lesions in infant monkeys. Neurosci Res Program Bull 1974;12:217-222.

32 Lemon RN, Griffiths J: Comparing the function of the corticospinal system in different species: organizational differences for motor specialization? Muscle Nerve 2005;32:261279.

33 Kuhtz-Buschbeck JP, Hoppe B, Golge M, Dreesmann M, Damm-Stunitz U, Ritz A: Sensorimotor recovery in children after traumatic brain injury: analyses of gait, gross motor, and fine motor skills. Dev Med Child Neurol 2003;45:821-828.

34 Kuhtz-Buschbeck JP, Stolze H, Golge M, Ritz A: Analyses of gait, reaching, and grasping in children after traumatic brain injury. Arch Phys Med Rehabil 2003;84:424-430.

-35 Katz-Leurer M, Rotem H, Lewitus H, Keren $\mathrm{O}$, Meyer S: Relationship between balance abilities and gait characteristics in children with post-traumatic brain injury. Brain Inj 2008;22:153-159.

- 36 Basford JR, Chou LS, Kaufman KR, Brey RH, Walker A, Malec JF, Moessner AM, Brown AW: An assessment of gait and balance deficits after traumatic brain injury. Arch Phys Med Rehabil 2003;84:343-349.

37 Williams G, Galna B, Morris ME, Olver J: Spatiotemporal deficits and kinematic classification of gait following a traumatic brain injury: a systematic review. J Head Trauma Rehabil 2010;25:366-374.

38 Walker WC, Pickett TC: Motor impairment after severe traumatic brain injury: a longitudinal multicenter study. J Rehabil Res Dev 2007;44:975-982.

39 Adelson PD, Fellows-Mayle W, Kochanek PM, Dixon CE: Morris water maze function and histologic characterization of two age-atinjury experimental models of controlled cortical impact in the immature rat. Childs Nerv Syst 2013;29:43-53.

40 Adelson PD, Dixon CE, Robichaud P, Kochanek PM: Motor and cognitive functional deficits following diffuse traumatic brain injury in the immature rat. J Neurotrauma 1997; 14:99-108.

41 Prins ML, Hovda DA: Traumatic brain injury in the developing rat: effects of maturation on Morris water maze acquisition. J Neurotrauma 1998;15:799-811.

42 Adelson PD, Dixon CE, Kochanek PM: Longterm dysfunction following diffuse traumatic brain injury in the immature rat. J Neurotrauma 2000;17:273-282.

43 Ajao DO, Pop V, Kamper JE, Adami A, Rudobeck E, Huang L, Vlkolinsky R, Hartman RE, Ashwal S, Obenaus A, Badaut J: Traumatic brain injury in young rats leads to progressive behavioral deficits coincident with altered tissue properties in adulthood. J Neurotrauma 2012;29:2060-2074.

44 File SE: Factors controlling measures of anxiety and responses to novelty in the mouse. Behav Brain Res 2001;125:151-157.

45 Lalonde R, Strazielle C: Relations between open-field, elevated plus-maze, and emergence tests as displayed by C57/BL6J and BALB/C mice. J Neurosci Methods 2008;171:48-52.

46 Depino AM, Gross C: Simultaneous assessment of autonomic function and anxiety-related behavior in $\mathrm{BALB} / \mathrm{c}$ and $\mathrm{C} 57 \mathrm{BL} / 6$ mice. Behav Brain Res 2007;177:254-260.

- 47 Kolb B, Gibb R, Gorny G: Cortical plasticity and the development of behavior after early frontal cortical injury. Dev Neuropsychol 2000;18:423-444.

48 Jacobs R, Harvey AS, Anderson V: Executive function following focal frontal lobe lesions: impact of timing of lesion on outcome. Cortex 2007;43:792-805.

49 Karver CL, Wade SL, Cassedy A, Taylor HG, Stancin T, Yeates KO, Walz NC: Age at injury and long-term behavior problems after traumatic brain injury in young children. Rehabil Psychol 2012;57:256-265. 
50 Spencer-Smith M, Anderson V: Healthy and abnormal development of the prefrontal cortex. Dev Neurorehabil 2009;12:279-297.

-51 Semple BD, Blomgren K, Gimlin K, Ferriero DM, Noble-Haeusslein LJ: Brain development in rodents and humans: identifying benchmarks of maturation and vulnerability to injury across species. Prog Neurobiol 2013; 106-107:1-16.

52 Kolb B, Holmes C, Whishaw IQ: Recovery from early cortical lesions in rats. III. Neonatal removal of posterior parietal cortex has greater behavioral and anatomical effects than similar removals in adulthood. Behav Brain Res 1987;26:119-137.

-53 Rudebeck PH, Walton ME, Millette BH, Shirley E, Rushworth MF, Bannerman DM: Distinct contributions of frontal areas to emotion and social behaviour in the rat. Eur J Neurosci 2007;26:2315-2326.
54 Rudebeck PH, Buckley MJ, Walton ME, Rushworth MF: A role for the macaque anterior cingulate gyrus in social valuation. Science 2006;313:1310-1312.

55 Martens KM, Vonder Haar C, Hutsell BA, Hoane MR: A discrimination task used as a novel method of testing decision-making behavior following traumatic brain injury. J Neurotrauma 2012;29:2505-2512.

56 Levin HS, Hanten G: Executive functions after traumatic brain injury in children. Pediatr Neurol 2005;33:79-93.

57 Hu P, Fan J, Xu P, Zhou S, Zhang L, Tian Y, Wang K: Attention network impairments in patients with focal frontal or parietal lesions. Neurosci Lett 2013;534:177-181.
Laviola G, Macri S, Morley-Fletcher S, Adriani W: Risk-taking behavior in adolescent mice: psychobiological determinants and early epigenetic influence. Neurosci Biobehav Rev 2003;27:19-31.

59 Spear L: Modeling adolescent development and alcohol use in animals. Alcohol Res Health 2000;24:115-123.

60 Salchner P, Lubec G, Singewald N: Decreased social interaction in aged rats may not reflect changes in anxiety-related behaviour. Behav Brain Res 2004;151:1-8.

61 Spreng M, Rossier J, Schenk F: Spaced training facilitates long-term retention of place navigation in adult but not in adolescent rats. Behav Brain Res 2002;128:103-108.

62 Cestari V, Lucidi A, Pieroni L, Rossi-Arnaud C: Memory for object location: a span study in children. Can J Exp Psychol 2007;61:13-20. 